\title{
A workplace feasibility study of the effect of a minimal fruit intervention on fruit intake
}

\author{
Sevil Alinia ${ }^{1, *}$, Anne D Lassen ${ }^{1}$, Kirstine S Krogholm², Tue Christensen ${ }^{1}$, Ole H Hels ${ }^{1}$ \\ and Inge Tetens ${ }^{1}$ \\ 'Department of Nutrition, National Food Institute, Technical University of Denmark, Mørkhøj Bygade 19, \\ DK-2860 Søborg, Denmark: ${ }^{2}$ Department of Toxicology and Risk Assessment, National Food Institute, \\ Technical University of Denmark, Søborg, Denmark
}

Submitted 21 September 2009: Accepted 5 August 2010: First published online 8 December 2010

\begin{abstract}
Objective: The main purpose of the study was to investigate the feasibility of using workplaces to increase the fruit consumption of participants by increasing fruit availability and accessibility by a minimal fruit programme. Furthermore, it was investigated whether a potential increase in fruit intake would affect vegetable, total energy and nutrient intake.

Design: A 5-month, controlled, workplace study where workplaces were divided into an intervention group (IG) and a control group (CG). At least one piece of free fruit was available per person per day in the IG. Total fruit and dietary intake was assessed, using two $24 \mathrm{~h}$ dietary recalls at baseline and at endpoint.

Setting: Eight Danish workplaces were enrolled in the study. Five workplaces were in the IG and three were in the CG.

Subjects: One hundred and twenty-four (IG, $n$ 68; CG, $n$ 56) healthy, mainly normal-weight participants were recruited.

Results: Mean daily fruit intake increased significantly from baseline to endpoint only in the IG by $112(\mathrm{SE} 35) \mathrm{g}$. In the IG, mean daily intake of added sugar decreased significantly by $10 \cdot 7(\mathrm{SE} 4 \cdot 4) \mathrm{g}$, whereas mean daily intake of dietary fibre increased significantly by $3 \cdot 0(\mathrm{SE} 1 \cdot 1) \mathrm{g}$. Vegetable, total energy and macronutrient intake remained unchanged through the intervention period for both groups.

Conclusions: The present study showed that it is feasible to increase the average fruit intake at workplaces by simply increasing fruit availability and accessibility. Increased fruit intake possibly substituted intake of foods containing added sugar. In this study population the increased fruit intake did not affect total energy intake.
\end{abstract}

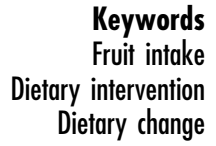

Keywords

tary intervention Dietary change
According to WHO, poor nutrition accounts for $4 \cdot 6 \%$ of the total disability-adjusted life-years (DALY) lost in the $\mathrm{EU}^{(1)}$, where one DALY represents the loss of one year of healthy life. An additional $3.7 \%$ of DALY are lost due to overweight and obesity. International experts conclude that the global obesity epidemic poses one of the largest threats to public health and that low fruit and vegetable consumption is among the top ten risk factors for mortality worldwide ${ }^{(2)}$. Moreover, WHO states that there is convincing evidence that consumption of a diet high in fruit and vegetables reduces the risk of obesity ${ }^{(2)}$. This is supported by a recent review suggesting that high fruit intake may be associated with low body weight ${ }^{(3)}$.

Several national food-based dietary guidelines recommend an increased consumption of fruit and vegetables ${ }^{(4,5)}$. In addition, a Nordic Plan of Action on better health and quality of life through diet and physical activity, adopted by the Nordic Council of Ministers, emphasizes the importance of reversing the alarming tendency of an increasing number of overweight and obese individuals in the Nordic region by different schemes such as enhancing the consumption of fruit and vegetables and reducing the consumption of added sugar $^{(6)}$.

In Denmark, only $16 \%$ of the adult population consumes the amount of fruit and vegetables that meets the official Danish recommendations of $600 \mathrm{~g} / \mathrm{d}^{(7,8)}$. At the same time, it is estimated that $55 \%$ of the adult Danish population is overweight $\left(\mathrm{BMI} \geq 25 \mathrm{~kg} / \mathrm{m}^{2}\right)$ and $15 \%$ is obese $\left(\mathrm{BMI} \geq 30 \mathrm{~kg} / \mathrm{m}^{2}\right)^{(8)}$. Thus, effective communitybased strategies that aim to promote healthy eating habits and increase the average fruit and vegetable consumption of the general population are much needed. Adopting workplaces for this purpose seems a suitable approach and is in accordance with recommendations from different international and regional bodies such as WHO, the Nordic Plan of Action, and Guidelines for the Prevention 
of Obesity at the Workplace (GPOW) Project ${ }^{(6,9,10)}$. The rationale behind this is that workplaces constitute appropriate settings for health promotion programmes as a substantial amount of the adult population attends a workplace each day and a relatively large number of individuals can be addressed simultaneously. Furthermore, one must assume that employers are interested in investing in their human resources and offering them healthy alternatives.

Several workplace-based programmes attempting to implement healthy dietary behaviour among employees have been conducted ${ }^{(11-17)}$. The majority of these studies aimed to change the overall dietary intake patterns of the participants through relatively extensive interventions including education and counselling. In the present workplace study, we attempted, through minimal intervention, to increase fruit consumption of the participants by addressing only two important determinants for increased fruit intake: availability and accessibility of fruit ${ }^{(18)}$. This decision was based upon the assumption that fruit can be introduced at a workplace relatively easily and without any radical demands such as extensive involvement of the canteen or other staff. Further, fruit can be consumed as a snack without any form of preparation and it does not require much modification of the physical environment of the workplace.

In addition to elevating the employees' fruit intake, implementation of free available fruit at the workplace may contribute to an alteration in their snacking habits. Fruit can be consumed as a between-meal snack and as such may substitute snacks that are relatively high in fat and added sugar, thereby decreasing total energy intake. Furthermore, consumption of fruit may affect satiety due to its low energy density and high water and dietary fibre content $^{(19,20)}$. Hence, intake of the subsequent meal and therefore the total energy intake may potentially be reduced.

The main purpose of the present study was to investigate the feasibility of using workplaces as settings to increase fruit consumption of the participants through minimal intervention by increasing fruit availability and accessibility, using a minimal fruit programme. A 'minimal fruit programme' is without any additional instructions, counselling or other health promotion activities and holds the advantages that it is relatively low in cost and easy to implement. Furthermore, it was investigated whether a possible increase in fruit intake would affect vegetable and nutrient intake and whether such an effect would influence the total energy intake.

\section{Materials and methods}

\section{Workplaces and participants}

Recruitment of the workplaces was carried out in cooperation with the Danish Cancer Society, who contacted the companies that supply fruit and asked them to place a briefing letter on their website, encouraging workplaces to enrol in the present study. Workplaces that were planning to offer free fruit to their employees and therefore contacted the company-fruit dealers could then, if interested, sign up for the study. The briefing letters were also distributed to 1000 workplaces, randomly selected from a company database provided by an information service company, and printed in a magazine published by a company sports union, which covered more than 150000 members. Furthermore, staff at the Danish Cancer Society were consulted about workplaces that were considering to introduce free fruit.

Eight workplaces in the Copenhagen area signed up for the study. The workplaces were allocated as intervention workplaces if they were planning to offer free fruit to their employees. Hence, five workplaces were enrolled as intervention workplaces. The remaining three workplaces, which had never had free fruit or were not considering having free fruit at the workplace at least for the following 6 months, were enrolled as control workplaces. The workplaces consisted mainly of white-collar workers with the exception of two, one in the intervention group and one in the control group, consisting mainly of blue-collar workers. Recruitment at the workplaces of individuals who were interested in participating in the study occurred through a contact person who was nominated at each workplace. A total of 146 participants, eighty-two in the intervention and sixty-four in the control group, were included at baseline. Pregnant and lactating women, and individuals who did not expect to be at the particular workplace at the study endpoint, were excluded from the study. The study protocol was accepted by the Ethics Committee of Copenhagen and Frederiksberg municipality (J. No. KA-20060047).

\section{Intervention}

Workplaces entered the study at distinct points in time, starting from June to September. Assessments were made both at baseline and at endpoint approximately 5 months later. The intervention was a fruit programme, consisting of a fruit basket that was set out in a room to which participants had free and easy access, such as the reception or the staff kitchen. At least one piece of fruit was available per participant per day. Fruits available were mainly apples, pears, oranges and bananas. The fruit programme stood alone in that the participants did not receive any further counselling, etc.

\section{Dietary assessment}

Dietary intake was assessed using a $24 \mathrm{~h}$ recall questionnaire, which was a modified form of the dietary record questionnaire from the Danish National Dietary Survey $2000-2002^{(21)}$. The $24 \mathrm{~h}$ recall has been validated with an objective biomarker of fruit intake ${ }^{(22)}$. The questionnaire was completed on two non-consecutive weekdays, covering the dietary intake of the previous weekday, carried out by trained interviewers in closed rooms, at baseline and endpoint. The software program General Intake Estimated Systems (GIES) version 0.995a 
(Danish Food Institute, Technical University of Denmark, Søborg, Denmark; released 26 June 2005) was used to calculate nutrient intake. Items included in the analysis were fruit, vegetables, total energy, fat, protein and total carbohydrates, as well as added sugar and dietary fibre separately. Added sugar was calculated as the sum of industrially manufactured refined sugars including sucrose, glucose, fructose and starch hydrolysates. The dietary fibre calculations were based on analytical values obtained by the AOAC method ${ }^{(21)}$.

\section{Background information}

Background variables such as sex, age, education and occupation were assessed using a background questionnaire based on the validated questionnaire from the Danish National Dietary Survey 2000-2002(21). Body weight and height were measured without shoes in light indoor clothing using a Soehnle Verona Quattrotronic digital scale (model 63686; Soehnle, Backnang, Germany) to the nearest $0 \cdot 1 \mathrm{~kg}$ and a Soehnle 5001 Ultrasonic Height Measure to the nearest $\mathrm{cm}$, respectively.

\section{Employee satisfaction}

At endpoint, participants from the intervention group were asked about their satisfaction level with the fruit programme. There were four levels of response option: (i) very satisfied; (ii) reasonably satisfied; (iii) less satisfied; or (iv) not satisfied.

\section{Statistical analysis}

Power analyses showed that with a mean expected difference of 100 (SD 220) g/d in fruit intake between intervention and control group, with a power of $80 \%$ and a significance level of $5 \%$, at least seventy-five participants were necessary in each group. Paired $t$ tests were performed in the intervention and control group separately to evaluate changes in intake from baseline to endpoint. Two-sample $t$ tests were performed to evaluate differences in changes from baseline to endpoint between the intervention and control group. The analyses were made using the Statistical Analysis Systems statistical software package version $9 \cdot 1$ (SAS Institute, Cary, NC, USA). Homogeneity of variance and normal distribution were confirmed by plots, histograms and Shapiro-Wilk's tests.

\section{Results}

At endpoint, the total number of participants was reduced from 146 to 124, sixty-eight in the intervention and fiftysix in the control group, due to unexpected end of employment or pregnancy.

\section{Baseline characteristics}

Baseline characteristics, including sex, age, educational level, occupation, smoking status and BMI, did not differ significantly between the intervention and control groups (Table 1). However, although non-significant, there was a larger proportion of women in the intervention group than in the control group. Additionally, participants in the intervention group tended to have a higher education than those in the control group. Both groups consisted predominantly of white-collar workers.

\section{Dietary intake}

Table 2 shows mean daily intake values with their standard errors for the intervention and control groups at baseline and endpoint for fruit (exclusive of juice), vegetables (exclusive of potatoes), energy and macronutrients (including added sugar and dietary fibre), which were assessed by using the two $24 \mathrm{~h}$ recall questionnaires. At baseline, no statistically significant differences in consumption variables were found between the intervention

Table 1 Baseline characteristics of intervention and control groups: employees from eight Danish workplaces enrolled in a workplace feasibility study of the effect of a minimal fruit intervention on fruit intake

\begin{tabular}{|c|c|c|c|c|}
\hline & \multicolumn{2}{|c|}{ Intervention group ( $n$ 68) } & \multicolumn{2}{|c|}{ Control group ( $n$ 56) } \\
\hline & Mean & SD & Mean & SD \\
\hline Age (years) & $46 \cdot 5$ & $9 \cdot 9$ & $44 \cdot 9$ & $8 \cdot 3$ \\
\hline \multirow[t]{2}{*}{ BMI $\left(\mathrm{kg} / \mathrm{m}^{2}\right)$} & $26 \cdot 2$ & $5 \cdot 2$ & $25 \cdot 2$ & $4 \cdot 0$ \\
\hline & \multicolumn{2}{|c|}{$\%$} & \multicolumn{2}{|c|}{$\%$} \\
\hline Sex female & \multicolumn{2}{|c|}{74} & \multicolumn{2}{|c|}{57} \\
\hline \multicolumn{5}{|l|}{ Education } \\
\hline Basic school & \multicolumn{2}{|c|}{6} & \multirow{2}{*}{\multicolumn{2}{|c|}{9}} \\
\hline Vocational education & \multirow{2}{*}{\multicolumn{2}{|c|}{$\begin{array}{l}22 \\
13\end{array}$}} & & 36 \\
\hline Short $(<3$ years) & & & \multicolumn{2}{|c|}{16} \\
\hline Medium length (3-4 years) & \multicolumn{2}{|c|}{32} & \multirow{2}{*}{\multicolumn{2}{|c|}{$\begin{array}{l}27 \\
13\end{array}$}} \\
\hline Long (>4 years) & \multicolumn{2}{|c|}{27} & & \\
\hline \multicolumn{5}{|l|}{ Occupation } \\
\hline Skilled & \multicolumn{2}{|c|}{2} & \multicolumn{2}{|c|}{4} \\
\hline Unskilled & \multicolumn{2}{|c|}{9} & \multicolumn{2}{|c|}{16} \\
\hline Office worker & \multicolumn{2}{|c|}{$\begin{array}{l}90 \\
18\end{array}$} & \multicolumn{2}{|c|}{80} \\
\hline Smoker & \multicolumn{2}{|c|}{18} & \multicolumn{2}{|c|}{14} \\
\hline
\end{tabular}


Table 2 Daily intake values in the intervention and control groups before and after the intervention, a Danish workplace feasibility study of the effect of a minimal fruit intervention on fruit intake

\begin{tabular}{|c|c|c|c|c|c|c|c|c|c|c|c|c|}
\hline & \multicolumn{6}{|c|}{ Intervention group ( $n$ 68) } & \multicolumn{6}{|c|}{ Control group ( $n$ 56) } \\
\hline & \multicolumn{2}{|c|}{$t=0$} & \multicolumn{2}{|c|}{$t=5$} & \multicolumn{2}{|c|}{$t=5-t=0$} & \multicolumn{2}{|c|}{$t=0$} & \multicolumn{2}{|c|}{$t=5$} & \multicolumn{2}{|c|}{$t=5-t=0$} \\
\hline & Mean & SE & Mean & SE & Mean & SE & Mean & SE & Mean & SE & Mean & SE \\
\hline Fruit (g) & 260 & 25 & $372^{\mathrm{a}}$ & 31 & 112 & 35 & 234 & 22 & 244 & 26 & $10^{b}$ & 24 \\
\hline Vegetables (g) & 192 & 15 & 209 & 20 & 17 & 15 & 210 & 15 & 206 & 17 & -4 & 15 \\
\hline Energy (MJ) & 8.9 & 0.4 & $9 \cdot 0$ & 0.4 & 0.1 & 0.4 & $9 \cdot 0$ & 0.3 & $9 \cdot 2$ & 0.5 & 0.2 & $0 \cdot 4$ \\
\hline Protein (g) & $79 \cdot 3$ & $3 \cdot 6$ & $84 \cdot 2$ & $3 \cdot 8$ & 4.9 & $3 \cdot 8$ & $78 \cdot 3$ & $3 \cdot 1$ & $79 \cdot 0$ & $3 \cdot 4$ & $0 \cdot 7$ & $3 \cdot 6$ \\
\hline Carbohydrate (g) & $249 \cdot 2$ & $10 \cdot 7$ & $251 \cdot 7$ & $10 \cdot 7$ & $2 \cdot 4$ & $11 \cdot 3$ & $267 \cdot 9$ & $9 \cdot 7$ & $273 \cdot 0$ & $13 \cdot 2$ & $5 \cdot 1$ & $11 \cdot 4$ \\
\hline Added sugar (g) & 43.9 & $4 \cdot 7$ & $33 \cdot 2^{\mathrm{a}}$ & $3 \cdot 6$ & $-10 \cdot 7$ & $4 \cdot 4$ & $50 \cdot 4$ & $4 \cdot 1$ & $45 \cdot 3$ & $5 \cdot 3$ & $-5 \cdot 1$ & $4 \cdot 4$ \\
\hline Dietary fibre $(\mathrm{g})$ & $20 \cdot 1$ & $1 \cdot 0$ & $23 \cdot 2^{a}$ & $1 \cdot 2$ & $3 \cdot 0$ & $1 \cdot 1$ & $22 \cdot 6$ & $1 \cdot 1$ & $23 \cdot 3$ & $1 \cdot 3$ & 0.7 & $1 \cdot 0$ \\
\hline Fat $(g)$ & $76 \cdot 0$ & 3.5 & $77 \cdot 1$ & $4 \cdot 2$ & $1 \cdot 1$ & $3 \cdot 8$ & $76 \cdot 5$ & $3 \cdot 6$ & $80 \cdot 2$ & $5 \cdot 6$ & $3 \cdot 7$ & $5 \cdot 3$ \\
\hline
\end{tabular}

$t=0$, intake at baseline; $t=5$, intake at endpoint; $t=5-t=0$, change from baseline to endpoint.

${ }^{\text {a }}$ Significant change from $t=0$ in the intervention group (fruit, $P=0.002$; added sugar, $P=0.019$; dietary fibre, $P=0.007$ ).

${ }^{\mathrm{b}} t=5-t=0$ in the control group significantly different from $t=5-t=0$ in the intervention group $(P=0 \cdot 021)$.

and control groups. After the intervention, mean daily fruit and dietary fibre consumption increased significantly by 112 (SE 35$) \mathrm{g}(P=0 \cdot 002)$ and $3 \cdot 0($ SE $1 \cdot 1) \mathrm{g}(P=0 \cdot 007)$, respectively, whereas there was a significant decrease of $10 \cdot 7($ se 4.4$) \mathrm{g}(P=0.019)$ in the mean daily consumption of added sugar in the intervention group. Mean daily intakes of vegetables, total energy and macronutrients remained unchanged in the intervention group. In the control group, no changes in any of the intake variables were observed from baseline to endpoint. Only the change in fruit intake was significantly different between the intervention group and the control group $(P=0 \cdot 021)$.

\section{Employee satisfaction}

The satisfaction level in the intervention group was as follows: $50 \%, 41 \%$ and $9 \%$ of the participants chose the first (very satisfied), second (reasonably satisfied) and third (less satisfied) option, respectively. The fourth option (not satisfied) was not selected by any of the participants. The number of individuals who selected options (i) and (ii) was significantly higher than those who selected option (iii) $(P<0 \cdot 001)$.

\section{Discussion}

The present feasibility study has shown that the 'minimal intervention' method used at workplace settings is a relatively easy and low-cost way to increase the daily intake of fruit significantly. Simple and easy methods that can increase the consumption of fruit in the general population are greatly warranted since this could contribute to a better nutritional status and reduction in overweight and obesity, and thus an overall reduction in DALY lost.

A number of other workplace intervention studies, aiming to implement healthy dietary behaviour among the participants, have been performed ${ }^{(11-17)}$, including the relatively extensive American 'Treatwell 5-a-Day worksite study'(16), the 'Seattle 5-a-Day Worksite Project ${ }^{(11)}$ and a less extensive Danish workplace study ${ }^{(15)}$. These studies achieved successful results in increasing the average fruit intake of the participants through a range of determinants, such as education and counselling of the participants and in some cases also families of the participants or other staff at the workplace. However, the present study differs from these studies at various levels, including the adoption of a relatively simple approach. The novel idea behind the present study was to investigate if application of a relatively minimal intervention in the form of increased availability and accessibility of fruit at workplaces can be an effective strategy to enhance the average fruit intake of the participants. Our results indicate that this was possible. It cannot be excluded that the dietary pattern of the participants may also have been affected in that the participants' intake of added sugar was decreased, suggesting a potential substitution of a part of the sugarsweetened food items in their diet with fruit.

In the study, no effect of increased fruit intake on the total energy intake was observed, which supports the suggestion that fruit was not added to the usual diet but may have substituted other food items in the diet. Other intervention studies have found an effect of increased fruit intake on total energy intake ${ }^{(23-27)}$. These intervention studies are either behavioural intervention studies, addressing several dietary and lifestyle factors among free-living individuals ${ }^{(24-26)}$, or clinical trials, implementing strict dietary regulations ${ }^{(23,27)}$. Common to all these studies is that participants were either overweight or obese and may thus have had a high motivation for weight reduction. It can be argued whether such intensive interventions are sustainable and possible to implement in everyday life. The present study explored if a minimal intervention was sufficient to generate a potential reduction in total energy intake among the participants. However, our participants were mainly of normal weight and may therefore not have had a strong incentive to reduce their total energy intake. Further, the participants had a relatively high baseline fruit intake and possibly 
therefore increased their daily fruit intake by only one piece of fruit during the intervention. While a decrease in the consumption of added sugar was observed, the reduction was not adequate to affect the total energy intake of the participants. Individuals with a lower fruit and higher total energy intake than the participants in the present study might have increased their fruit intake more extensively and substituted a larger proportion of their usual diet with fruit, which potentially could have been reflected in their total energy intake.

Although the present minimal intervention has shown to be an effective initiative to increase participants' fruit intake at the enrolled workplaces, some limitations should be considered. Workplaces were all from the Copenhagen area and the majority of the participants consisted of white-collar workers. Hence, extrapolation of the results to other areas and to individuals with a different occupational profile should be done with caution. Because the workplaces purchased the fruit themselves, the allocation of the workplaces and the participants to the intervention or the control group was self-selected and not randomized. This reduces the generalizability of the findings because participants in the intervention group may have been more motivated to increase their fruit intake than participants at an average workplace. Moreover, due to the self-purchased fruit, only a small number of the workplaces, initially approached, chose to enrol in the study, increasing the risk of selection bias.

In conclusion, the current study suggests that it is feasible to increase the fruit intake of employees by increasing the availability and accessibility of fruit at workplaces, using a minimal intervention method. Additionally, dietary fibre intake of the participants was increased, whereas intake of added sugar was reduced and possibly substituted with fruit. One additional piece of fruit per day was not sufficient to affect total energy intake in this study population, suggesting a substitution effect. In future minimal interventions of this kind, it would be interesting to examine if inclusion of overweight or obese participants with a relatively low fruit intake prior to the study and a potentially greater incentive to reduce body weight would result in a change in total energy intake. Further, future intervention studies need to be randomized in order to provide more robust and generalizable results.

\section{Acknowledgements}

Sources of funding: European Commission. Conflicts of interest: None. Author contributions: A.D.L. and K.S.K. were involved in planning the study and recruitment/interview of the workplaces/participants. T.C. performed the nutrient calculations. O.H.H. conducted the statistical analyses. I.T. contributed to planning of the study. All co-authors contributed to the writing process of the manuscript. Acknowledgements: This study is part of the ISAFRUIT project, funded by the European Commission under
'Thematic Priority 5 - Food Quality and Safety' of the 6th Framework Programme of RTD (contract no. FP6-FOODCT-2006-016279). The views and opinions expressed in this publication are purely those of the writers and may not in any circumstances be regarded as stating an official position of the European Commission. The authors are grateful to the leadership and the employees of all worksites who participated in this study. Furthermore, the authors thank Dr Amelia A. Lake, Research Fellow at the Human Nutrition Research Centre, IHS, Newcastle University, for her contribution and proofreading of the manuscript.

\section{References}

1. Robertson A, Tirado C, Lobstein T et al. (2004) Food and Health in Europe: A New Basis for Action. WHO Regional Publications European Series no. 96. Copenhagen: WHO Regional Office for Europe.

2. World Health Organization (2003) Diet, Nutrition and the Prevention of Chronic Diseases. Joint WHO/FAO Expert Consultation. WHO Technical Report Series no. 916. Geneva: WHO.

3. Alinia S, Hels O \& Tetens I (2009) The potential association between fruit intake and body weight - a review. Obes Rev 10, 639-647.

4. Ovesen L, Andersen NL, Dragsted LO et al. (2002) Frugt, grønt og helbred - Opdatering af vidensgrundlaget. Søborg: Ministry of Food, Agriculture and Fisheries.

5. US Department of Health and Human Services \& US Department of Agriculture (2005) Dietary Guidelines for Americans. Washington, DC: US Government Printing Office.

6. Nordic Council of Ministers (2006) A Better Life Through Diet and Physical Activity. Nordic Plan of Action on Better Health and Quality of Life Through Diet and Physical Activity. Copenhagen: Nordic Council of Ministers.

7. Fagt S, Biltoft-Jensen A, Matthiessen J et al. (2008) Dietary Habits of Denmark 1995-2006. Status and Development with Focus on Fruits, Vegetables and Added Sugar. Søborg: National Food Institute, Technical University of Denmark.

8. Astrup A, Andersen NL, Stender S et al. (2005) Danish Dietary Recommendations 2005. Søborg: Danish Institute for Food and Veterinary Research.

9. Karnaki P, Zota D \& Lenos A (2009) Guidelines for the Prevention of Obesity at the Workplace. Athens: Institute of Preventive Medicine Environmental and Occupational Health - PROLEPSIS

10. World Health Organization/World Economic Forum (2008) Preventing Noncommunicable Diseases in the Workplace Through Diet and Physical Activity: WHO/World Economic Forum Report of a Joint Event. Geneva: WHO/WEF.

11. Beresford SA, Thompson B, Feng Z et al. (2001) Seattle 5 a Day worksite program to increase fruit and vegetable consumption. Prev Med 32, 230-238.

12. Buller DB, Morrill C, Taren D et al. (1999) Randomized trial testing the effect of peer education at increasing fruit and vegetable intake. J Natl Cancer Inst 91, 1491-1500.

13. Elliot DL, Goldberg L, Kuehl KS et al. (2007) The PHLAME (Promoting Healthy Lifestyles: Alternative Models' Effects) firefighter study: outcomes of two models of behavior change. J Occup Environ Med 49, 204-213.

14. Engbers LH, van Poppel MN, Chin AP et al. (2006) The effects of a controlled worksite environmental intervention on determinants of dietary behavior and self-reported fruit, vegetable and fat intake. BMC Public Health 6, 253. 
15. Lassen A, Thorsen AV, Trolle E et al. (2004) Successful strategies to increase the consumption of fruits and vegetables: results from the Danish ' 6 a day' Work-site Canteen Model Study. Public Health Nutr 7, 263-270.

16. Sorensen G, Stoddard A, Peterson K et al. (1999) Increasing fruit and vegetable consumption through worksites and families in the Treatwell 5-a-day study. Am J Public Health 89, 54-60.

17. Sternfeld B, Block C, Quesenberry CP Jr et al. (2009) Improving diet and physical activity with ALIVE: a worksite randomized trial. Am J Prev Med 36, 475-483.

18. Lassen A, Hansen K \& Trolle E (2007) Comparison of buffet and à la carte serving at worksite canteens on nutrient intake and fruit and vegetable consumption. Public Health Nutr 10, 292-297.

19. Flood-Obbagy JE \& Rolls BJ (2009) The effect of fruit in different forms on energy intake and satiety at a meal. Appetite 52, 416-422.

20. Spiller GA (2001) CRC Handbook of Dietary Fiber in Human Nutrition. Boca Raton, FL: CRC Press.

21. Lyhne N, Christensen T, Groth MV et al. (2005) Dietary Habits in Denmark 2000-2002. Main Results. Søborg: Danish Institute for Food and Veterinary Research.
22. Krogholm KS, Bredsdorff L, Alinia S et al. (2010) Free fruit at workplace intervention increases total fruit intake: a validation study using $24 \mathrm{~h}$ dietary recall and urinary flavonoid excretion. Eur J Clin Nutr (Epublication ahead of print version).

23. de Oliveira MC, Sichieri R \& Venturim MR (2008) A lowenergy-dense diet adding fruit reduces weight and energy intake in women. Appetite 51, 291-295.

24. Ledikwe JH, Blanck HM, Kettel KL et al. (2006) Dietary energy density is associated with energy intake and weight status in US adults. Am J Clin Nutr 83, 1362-1368.

25. Thomson CA, Rock CL, Giuliano AR et al. (2005) Longitudinal changes in body weight and body composition among women previously treated for breast cancer consuming a high-vegetable, fruit and fiber, low-fat diet. Eur J Nutr 44, 18-25.

26. Svendsen M, Blomhoff R, Holme I et al. (2007) The effect of an increased intake of vegetables and fruit on weight loss, blood pressure and antioxidant defense in subjects with sleep related breathing disorders. Eur J Clin Nutr 61, 1301-1311.

27. Rodriguez MC, Parra MD, Marques-Lopes I et al. (2005) Effects of two energy-restricted diets containing different fruit amounts on body weight loss and macronutrient oxidation. Plant Foods Hum Nutr 60, 219-224. 